Reviews

electoral democracies. D. Rawson considers the contradictory tendencies toward centralization and decentralization in pre-colonial states, the French colonial administration, and the various post-independence governments as well as the challenges that these offer to plans for democratic decentralization. J.U. Davis looks at the opportunities for political socialization offered by diverse local groups and stresses the importance of capacity building to facilitate their inclusion in the democratic process. N. Mezey focuses on health and the way in which unequal gender roles constrain women's access to and use of health care, proposing some alternatives for health-care financing. R.J. Bingen's article looks at a variety of agricultural interest groups, their relationships with one other and with the central administration; he suggests that greater decentralization is likely to lead to greater access to the state by these groups because the nature of state centralization and concentration will change. Finally, C. Diarrah outlines the contemporary challenges to the institutionalization of Malian democracy and efforts by the government to meet them; although placed formally in a separate epilogue, this article fits thematically in the third section.

Several of these articles provide historical perspectives of Malian political change; although they are all valuable, D. Rawson's is particularly comprehensive and noteworthy. While recognizing the achievements that Mali has made in creating multi-party democracy, all the authors recognize the broader institutional and grassroots changes that need to occur in order to strengthen and deepen the process; elections are a only a necessary beginning. The articles also reflect some of the controversies that have marked interpretations of recent Malian history, for example, the extent to which previous regimes were actually able to carry out their centralizing schemes. So, while A. Clark emphasizes the repressiveness of the pre-democracy regime of Moussa Traoré, R.J. Bingen notes the ineffectiveness of central government attempts to transform the countryside.

This book is an important contribution for those interested in Mali, in French-speaking Africa, or the savanna countries of West Africa. Political and economic changes are occurring very quickly in Mali; a few of those discussed here have already been overtaken by events, yet these articles offer an invaluable evaluation of the situation at the end of the 1990s. Another outstanding feature of the collection as a whole is the dedication of the authors to explanatory frameworks that emphasize the factors within Mali that enabled contemporary change; while some might suggest that this gives insufficient attention to larger questions of the relationship of these changes to international political economy, it offers a refreshing corrective to analysts who slight the local context to privilege global issues. Overall this is a fine collection of works about the contemporary Malian political economy

\title{
The Economic Evolution of American Health Care: From Marcus Welby to Managed Care by David D. Dranove. Princeton: Princeton University Press (2000), 211 pp.
}

\section{Reviewed by Merrill Eisenberg, College of Public Health, The University of Arizona, Tucson.}

For all of you who are wondering just exactly how our health care system came to be so dreadful, David Dranove has the answers. Dranove was a student of Alain Enthoven, the Stanford based health care economist who was one of the architects of managed care as we know it in the US today. His book The Economic Evolution of American Health Care, tells the story of the recent paradigm shift in health care that has taken place over the past two decades. This book is not a critical analysis of the changes that have occurred - Dranove is a champion of paradigm. The book is an informative narrative - an emic description from an industry insider of how business and economic concerns rose to ascendancy and now control health care in the US. It is written for the lay reader and does an excellent job of explaining how we got to managed care and the issues that drive its continuing development.

Dranove, like his mentor Enthoven, is a champion of market forces. He not only explains, but celebrates the economic rationale for what appears to many Americans to be the erosion of both access to and the quality of basic health care services that has accompanied the transition to managed care in the US. From a market perspective, the problem with the traditional fee for service medical care system is the "shopping problem" (pp. 8-14) - the consumer has no incentive to shop for the best value in health care, since a third party is footing the bill. While he acknowledges that empirical evidence for improvement in health care quality and efficiency under managed care is largely equivocal, he defends the market approach with a fervor that borders on the religious.

Dranove traces the history of managed care back to the $1890 \mathrm{~s}$, when fraternal organizations and associations

Journal of Political Ecology

Vol. 82001 
Reviews

of workers created prepaid medical lodges to provide health care to members for a cost of $\$ 1$ - $\$ 2$ per year per member. At that time, more than one third of all families, mostly in low-income brackets, were covered by these lodges. Dranove follows the development of health care reimbursement schemes throughout the 20th century, touching on prepaid plans for work-related injury and illness in the 1920s, and the emergence of Blue Cross and Blue Shield in the 1930s. The Kaiser system was created in the 1940s, providing complete coverage for ten cents per day, per employee. These early third party reimbursement systems were small, and by 1950 , only $10 \%$ of heath care costs in the US were paid by third party payers. It wasn't until the 1950s, when antibiotics and anesthetics lowered the mortality rate in hospitals, that demand for hospital insurance began to rise. By the 1960s, the majority of working adults were covered by health insurance, which paid $21 \%$ of medical costs. During the early 1960 s, states began to provide coverage for the elderly and poor and in 1965 the federal Medicaid and Medicare programs were established. It is then that health care costs began to rise precipitously as a percentage of gross domestic product, with hospital costs being the largest component of overall costs.

Government attempts to curb the rate of health care cost increase during the 1970s and early 80s are described. Dranove downplays efforts such as community based planning, rate setting, and certificate of need requirements, calling them "a waste of time and effort" (p. 63). However, the political power of the health care industry ensured that regulatory health care cost containment efforts were attempted only half-heartedly in all but a handful of states, primarily Connecticut, Rhode Island, Massachusetts, Maryland and New Jersey. In those states, costs were indeed contained. As one veteran Connecticut regulator told me, the "...quality of the leadership and determination to duke it out with the industry" are what made the regulatory approach successful in these states. For example, in Connecticut, a strong rate-setting program resulted in health care costs that were $\$ 300$ million lower over a seven year period of time than they would have been if costs had increased with the national average. (Forand, personal communication, May, 2001). Hadley and Swartz (1989) studied hospital costs in 43 large standard metropolitan statistical areas and found that hospital regulation was the single most important factor leading to the slowdown in the rate of increase between 1980 and 1984. In Dranove's opinion, these efforts were misguided and useless, and in some cases, "did more harm than good." (p. 63). He states that "the failure of government cost containment efforts forced businesses to seek their own solution" to rising health care costs (p. 65).

Managed care to the rescue! Dranove describes how his mentor, Alain Enthoven, along with Paul Ellwood and Harold Luft "began spreading the word about HMOs" (p. 66) in the 1970s and 1980s. We learn about how these pioneers in the movement enlisted the support of local business groups, and how business leaders were invited to Ellwood's vacation condo in Jackson Hole to map out the principles of "managed competition" in conjunction with Bush administration officials. Dranove credits HMO "evangelists" (p. 67) with increasing HMO enrollment from 9.1 million in 1980, to 33.6 million in 1990, and applauds the fact that today, more than $80 \%$ of working Americans are enrolled in some type of managed care plan.

Dranove does a good job of describing different forms of managed care organizations (MCOs) that have emerged, delving into the alphabet soup of HMOs, IPAs, and PPOs as well as explaining the difference between a staff and group model HMO and other industry buzz words. He clearly outlines the strategies that MCOs use to curtail health care costs, including selective contracting (demanding large discounts from providers in exchange for steering a large volume of patients to that provider), using "innovative incentives" for primary care gatekeepers (creating incentives for providers to withhold treatment), and instituting utilization review (allowing the payer, not the doctor, to determine the appropriate course of treatment).

After reviewing the research Dranove concedes that there "there is clearly no best way to use incentives to balance concerns about cost and quality. There are always trade-offs" (p. 76). He also concedes that there is no definitive evidence that utilization review affects either cost of quality. Nevertheless, he is not ready to give up on these strategies and asks for more time for the industry to tinker with these approaches in order to find the optimal strategy.

Dranove cites evidence that MCOs have reduced health care costs by selective contracting and by reducing the acquisition and use of costly technologies. However, he states that the effect of managed care on quality is "ambiguous" (p. 87). He dismisses patient perceptions of poor care as misguided because patients do not define quality properly. "Unless and until consumers take a more sophisticated view of quality, HMOs will necessarily look bad in comparison with traditional fee-for-service medicine" (p. 89). He admits that the US public does not trust MCOs, and blames the newspapers for publishing accounts of MCO "horror stories" (pp. 89-90).

He explains that managed care has caused providers to contain costs by shifting many procedures from inpatient to outpatient settings, and by cutting back on uncompensated care and research. With regard to the latter, he says the public will just have to accept this situation or the government will have to start funding it. In a market based health care system, medical research and health care for the uninsured are someone else's problem.

Dranove describes other strategies for cutting costs while improving quality that have become popular in the 
industry, including the institution of continuous quality improvement (CQI) programs to eliminate mistakes in existing processes, and reengineering by introducing new systems, making major organizational changes, and adopting treatment guidelines and disease management programs. He is especially hopeful about the development of disease management guidelines, telling us that their development has become "an opportunity to make a profit" (p. 99) and that many consulting organizations have taken advantage of this opportunity.

While applauding the fact that efforts to improve quality and efficiency have spawned new business opportunities, Dranove reviews the research and concludes that there is not strong evidence that either CQI or reengineering have had an impact on cost or quality. He nevertheless believes that disease management guidelines have a great potential for eliminating inappropriate variations in medical practice.

Dranove moves on to describe how hospitals and hospital networks use the competitive system to maximize their revenues, how physicians have been forced to get business educations, and how this new efficient system has created a need for a whole new class of professional services - physician practice management and pharmacy benefits management. He reviews the importance of data for strategic planning in a market based health care system and how generating those data is now yet another new and lucrative business opportunity. A competitive system also requires providers to make substantial investments in marketing so they can "evaluate their competitive position, attempt to differentiate themselves from the crowd, and price accordingly" (p. 102). That money is being diverted from direct service into these new industry support systems is evidently not a concern.

A long chapter is devoted to the intricacies of measuring quality of care. In a competitive system, consumers should have information about quality in order to make informed choices. Various measures, their strengths and shortcomings are described. Dranove concludes that not only are better measures necessary, but consumers and providers must change the way they think about quality.

Competition among MCOs is addressed and as with many other topics in this book, Dranove states that there is no direct evidence that competition has resulted in cost savings for consumers. Competition has, however, led to a wave of mergers and acquisitions involving not only MCOs, but hospitals, physicians, and other types of providers as well. Systems have also merged vertically - with hospitals, nursing homes, outpatient clinics and diagnostic facilities, and physicians being reorganized under one umbrella. This is the point where Dranove starts to get nervous about the direction in which economic incentives are driving the industry. He cautions against mergers that do not "create value" (p. 129) and is especially fearful of provider mergers because when providers band together there is less competition in the marketplace and MCOs lose their negotiating advantage. Dranove favors using antitrust laws to keep this from occurring.

In the end, Dranove tells us that managed care has saved us millions of dollars, but that it must continue to evolve to remain economically viable. He calls for continued investment in outcomes research to enable MCOs to identify cost-effective approaches to treatment and disease management, and quality research to develop information so that patients can make informed choices about providers and MCOs. Dranove is optimistic about the future of managed care as long as markets remain competitive and information is available for patients and MCOs to make informed choices.

As one of those uninformed consumers, I fail to see how I have any choice or how I have benefited from the market-based health care economy. My state offers University employees one HMO "choice", and I have had four primary care physicians in four years because of mergers, closings, and HMO errors. My rates have gone up, I wait months for routine appointments and days for sick ones, I must arrive at the pharmacy on a particular day to refill prescriptions, and getting a new prescription filled takes several phone calls between the doctor and pharmacist to identify a drug my policy will pay for. On a personal level, I am clearly conceptualizing quality health care from the old paradigm. Dranove's book provides the mental map of those who have conceptualized and implemented a new paradigm. It's an interesting, informative, and maddening read.

\section{Reference Cited:}

Hadley J, and Swartz, K.

1989. "The impacts of hospital costs between 1980 and 1984 of hospital rate regulation, competition, and changes in health insurance coverage.” Inquiry 26:35-47. . 